\title{
Transcriptional and translational expression patterns associated with immobilized growth of Campylobacter jejuni
}

\author{
Balamurugan Sampathkumar, ${ }^{3} \dagger$ Scott Napper, ${ }^{1} \dagger$ Catherine D. Carrillo, ${ }^{2}$ \\ Philip Willson, ${ }^{1}$ Eduardo Taboada, ${ }^{2}$ John H. E. Nash, ${ }^{2}$ Andrew A. Potter, ${ }^{1}$ \\ Lorne A. Babiuk ${ }^{1}$ and Brenda J. Allan ${ }^{1}$ \\ ${ }^{1}$ Vaccine and Infectious Disease Organization, University of Saskatchewan, 120 Veterinary \\ Road, Saskatoon, Saskatchewan, Canada S7N 5E3 \\ ${ }^{2}$ Institute for Biological Sciences, National Research Council of Canada, 100 Sussex Road, \\ Ottawa, Ontario, Canada K1A OR6 \\ ${ }^{3}$ Agriculture and Agri-Food Canada, Lacombe Research Centre, 6000 C\&E Trail, Lacombe, \\ Alberta, Canada T4L 1W1
}

\begin{abstract}
Although Campylobacter jejuni is a leading cause of food-borne illness, little is known about the mechanisms by which this pathogen mediates prolonged environmental survival or host cell virulence. Although these behaviours represent distinct phenotypes, they share a common requirement of an immobilized state. In order to understand the cellular mechanisms that facilitate a surface-associated lifestyle, transcriptional and translational expression profiles were determined for sessile and planktonic C. jejuni. These investigations indicate that the immobilized bacteria undergo a shift in cellular priorities away from metabolic, motility and protein synthesis capabilities towards emphasis on iron uptake, oxidative stress defence and membrane transport. This pattern of expression partially overlaps those reported for Campylobacter during host colonization, as well as for other species of bacteria involved in biofilms, highlighting common adaptive responses to the conserved challenges within each of these phenotypes. The adaptation of Campylobacter to immobilized growth may represent a quasi-differentiated state that functions as a foundation for further specialization towards phenotypes such as biofilm formation or host cell virulence.
\end{abstract}

Received 3 August 2005

Revised 21 October 2005

Accepted 10 November 2005

\section{INTRODUCTION}

Campylobacter jejuni is the leading cause of bacterial foodborne illness in humans (Ketley, 1997), with contaminated poultry products representing the leading cause of human infection (Berndtson et al., 1996). Acute C. jejuni infection results in watery to bloody diarrhoea, fever, nausea and vomiting. Although the majority of infections are selflimiting, more serious medical conditions such as reactive arthritis, inflammatory bowel syndrome, Miller-Fisher syndrome (MFS) and Guillain-Barré syndrome (GBS) (Nachamkin et al., 1998) can result.

Unlike many bacterial pathogens, C. jejuni does not grow effectively outside the host. The ability of this bacterium to remain as the most frequent cause of food-borne illness, despite these fastidious growth requirements, is referred to

tThese authors contributed equally to this work.

The Gene Expression Omnibus Repository accession number for the microarray experiments reported in this paper is GSE3028. as the Campylobacter conundrum (Jones, 2001). Of particular relevance to food-borne infections is that the growth requirements of $C$. jejuni do not permit proliferation on contaminated foods under normal storage conditions (Park, 2002). While limited in its ability to proliferate, Campylobacter can survive for extended periods in the environment (Park, 2002) and has been isolated from a number of ecosystems (Altekruse et al., 1999; Bolton et al., 1987; Jones \& Bradshaw, 1996; Pearson et al., 1993; Stanley et al., 1998).

For Campylobacter, and other bacteria, the vast majority of growth within natural ecosystems occurs in association with a surface (Kirchman \& Mitchell, 1982; Kuhn et al., 1987). In the ecosystem, surface-associated growth can lead to the formation of highly structured, sessile microbial communities known as biofilms. Biofilm development is believed to occur through a series of coordinated stages including (i) transport of micro-organisms to a surface, (ii) initial attachment, (iii) formation of microcolonies, and (iv) formation of mature biofilms (van Loosdrecht et al., 
1990). Growth on an agar surface, with increased population densities and the associated challenges, bears functional resemblance to the second and third stages of biofilm formation, prior to the encapsulation that defines the biofilm phenotype.

There have been numerous genomic and proteomic investigations of biofilms involving various species of bacteria (Lazazzera, 2005). While these investigations do not identify a consensus pattern of gene expression, they do present a relatively cohesive picture of the adaptations underlying the phenotype. As considerable variation exists in the specifics of each biofilm, inconsistencies in expressional response are anticipated. Investigations of phenotypic features that are conserved throughout all biofilms, such as immobilization, are more likely to identify conserved cellular response elements.

Establishment of infection is also dependent upon immobilization during adhesion to intestinal cells. As the ability to grow on surfaces and adhere to intestinal epithelial cells is necessary for production of disease (de Melo \& Pechere, 1990; Russell \& Blake, 1994), growth on the surface of agar has been applied as a model for gene expression during initial stages of host infection (Wang et al., 2004). In these investigations Salmonella typhimurium grown on conventional agar showed surface-specific upregulation of genes associated with virulence, including those for lipopolysaccharide synthesis, iron metabolism and type III secretion (Wang et al., 2004).

Complex phenotypes, including virulence and biofilm formation, are often the cumulative result of parallel responses to different facets of a particular challenge. These phenotypes can be dissected, and associated responses partitioned, through models that incorporate a limited number of the associated stimuli. For example, through examination of responses to surface-associated growth, adaptations associated with immobilization can be distinguished from responses unique to specialized phenotypes such as biofilms.

In this investigation genomic and proteomic approaches were utilized to characterize differential patterns of expression of C. jejuni in response to immobilized growth conditions. Growth on agar resulted in the induction of a discrete number of functional systems directed towards the biological objectives of (i) iron acquisition, (ii) management of oxidative stress, (iii) membrane modifications and (iv) primary active-transport systems. Surface-associated growth also demonstrated a corresponding repression of systems involved in (i) energy production, (ii) motility, (iii) protein synthesis and (iv) non-essential iron-requiring proteins.

\section{METHODS}

Bacteria and culture conditions. Campylobacter jejuni NCTC 11168, obtained from the American Type Culture Collection (ATCC $700819)$, was used. A loopful of frozen $\left(-80^{\circ} \mathrm{C}\right)$ culture was streaked on Mueller-Hinton $(\mathrm{MH})$ agar plates and incubated at $37^{\circ} \mathrm{C}$ for $24 \mathrm{~h}$ under microaerophilic conditions $\left(10 \% \mathrm{CO}_{2}, 5 \%\right.$ $\mathrm{O}_{2}, 85 \% \mathrm{~N}_{2}$ ) created using a CampyPack plus (Becton Dickson Microbiology Systems). Following incubation, cells were collected using a sterile loop, resuspended in $1.0 \mathrm{ml} \mathrm{MH}$ broth and transferred to $50 \mathrm{ml}$ sterile $\mathrm{MH}$ broth in $25 \mathrm{~cm}^{2}$ tissue culture flasks with $0.4 \mu \mathrm{m}$ filter caps, followed by incubation for $24 \mathrm{~h}$ in the abovementioned conditions. The resulting culture was used as a stock culture for growth on agar and in broth. Growth in broth was achieved by transferring $1.0 \mathrm{ml}$ of the stock culture to $50 \mathrm{ml} \mathrm{MH}$ broth in tissue culture flasks (described above) and incubating microaerobically. At various times, samples were removed to determine the viable cell counts by plating serial dilutions of the culture on $\mathrm{MH}$ agar. Growth on agar was achieved by transferring $1.0 \mathrm{ml}$ stock culture onto a fresh $\mathrm{MH}$ agar plate, spreading the culture to produce a lawn, and incubating microaerobically. Samples were harvested by washing cells from the plates with $2 \cdot 0 \mathrm{ml} 0 \cdot 1 \mathrm{M}$ phosphate-buffered saline $(\mathrm{pH} 7 \cdot 4)$. Viable cell counts were determined as described above.

Genomic analysis. C. jejuni cells were harvested after $16 \mathrm{~h}$ growth on agar or in broth and homogenized in TRIzol (Invitrogen) by passing the mixture through a syringe. Nucleic acids (RNA and DNA) were isolated as recommended by the manufacturer. RNA was quantified spectrophotometrically at $260 \mathrm{~nm}$ using an ND-1000 spectrophotometer (Nanodrop). Preparation of complementary DNA (cDNA) and indirect labelling with Cy3 and Cy5 were performed as previously described (Carrillo et al., 2004). Samples were probed with the whole-genome C. jejuni NCTC 11168 microarray (version 3.0). Details of the construction and content of the microarray are available at (http://ibs-isb.nrc-cnrc.gc.ca/ibs/immunochemistry/ campychips_e.html). Slides were scanned using a Chipreader (Bio$\mathrm{Rad}$ ), and image analysis, signal normalization and data visualization were performed using Array Pro Analyser 4.5 (Media Cybernetics). Net signal intensities were obtained by performing local-ring background subtraction and spots with a signal less than 3SD of background in both channels were excluded from the analysis. The mean signal intensities for duplicate spots were averaged and data from each channel were adjusted by subarray normalization using crosschannel Lowess regression.

ArrayStat (Imaging Research) was used for statistical analysis of the replicated data. A proportional model with offsets, for dependent data, was selected and statistical significance was determined using the pooled common error method with the false discovery rate multiple test correction (nominal alpha $=0 \cdot 05$ ). Four biological replicates were tested, including one comparison in which the Cy3 and Cy5 dyes were swapped to compensate for biases caused by differing chemical properties of the fluorescent dye molecules. Complete results for these experiments are available at the Gene Expression Omnibus Repository (NCBI, http://www.ncbi.nlm.nih.gov/geo/) under accession number GSE3028.

\section{Proteomic analysis}

SDS-PAGE of total cellular and detergent-insoluble outermembrane proteins. Total cellular proteins were obtained by soni-

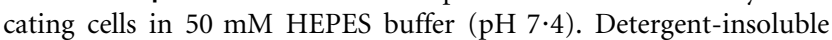
outer-membrane proteins from the cell pellets were obtained as described previously (Sampathkumar et al., 2004). The extracted proteins were quantified using the dye-binding assay of Bradford (1976) and $8.0 \mu \mathrm{g}$ of the protein preparation was separated by SDS-PAGE $(4 \cdot 0 \%$ stacking gel and $12 \cdot 0 \%$ resolving gel) using a Bio-Rad Protean II electrophoresis system. The gels were silver stained according to the manufacturer's instructions (Amersham Biosciences). 
Two-dimensional polyacrylamide gel electrophoresis (2D-PAGE) of total cellular proteins. Sample preparation. Total cellular protein was extracted by sonicating cell pellets in $1.0 \mathrm{ml}$ lysis buffer [8 M urea, $4.0 \%(\mathrm{w} / \mathrm{v})$ CHAPS, $40 \mathrm{mM}$ DTT and $2 \cdot 0 \%(\mathrm{v} / \mathrm{v})$ IPG pH 3-10 buffer] once for $15 \mathrm{~s}$ at $40 \Omega$ amplitude on ice. The extracts were centrifuged at $16000 \mathrm{~g}$ for $10 \mathrm{~min}$ to remove cell debris. The resulting supernatant was treated with $0 \cdot 1$ vol. buffer containing $50 \mathrm{mM} \mathrm{MgCl}_{2}, 1 \mathrm{mg}$ DNase $\mathrm{I} \mathrm{ml}^{-1}$ and $0.25 \mathrm{mg}$ RNase A ml $\mathrm{Al}^{-1}$. The reaction was stopped after $15 \mathrm{~min}$ at $4{ }^{\circ} \mathrm{C}$ with 3 vols ice-cold acetone. Proteins were then precipitated for $2 \mathrm{~h}$ at $-20^{\circ} \mathrm{C}$. The precipitate was collected by centrifugation at $3700 \mathrm{~g}$ for $15 \mathrm{~min}$ and resuspended in IPG gel rehydration solution $[8.0 \mathrm{M}$ urea, $2 \%(\mathrm{w} / \mathrm{v})$ CHAPS, $40 \mathrm{mM}$ DTT, $0.5 \%(\mathrm{v} / \mathrm{v}) \mathrm{pH} \mathrm{3.0-10.0} \mathrm{IPG} \mathrm{buffer}$ and $0.01 \%(\mathrm{w} / \mathrm{v})$ bromophenol blue]. The dye-binding assay of Bradford (1976) was then performed to quantify the protein concentration.

Isoelectric focusing. Protein extracts were subjected to high-resolution 2D-PAGE according to the method described by O'Farrell (1975) and modified by Görg et al. (2000). Equal amounts of proteins $(450 \mu \mathrm{g})$ were loaded onto a first-dimension gel strip. Isoelectric focusing was performed using an IPGphor electrophoresis unit with the Immobiline DryStrip Kit (Amersham Biosciences). Thirteen-centimetre Immobiline DryStrip gels ( $\mathrm{pH} 4 \cdot 0-7 \cdot 0$ ) were rehydrated in $250 \mu \mathrm{lPG}$ gel rehydration solution (composition as above except that IPG buffer $\mathrm{pH} 4 \cdot 0-7 \cdot 0$ was used) containing $450 \mu \mathrm{g}$ protein for $16 \mathrm{~h}$ at room temperature. Isoelectric focusing was achieved when the total running time yielded $60 \mathrm{kVh}$ at $20^{\circ} \mathrm{C}$. Following isoelectric focusing, the gels were equilibrated twice for 15 min each in $10.0 \mathrm{ml}$ isoelectric focusing gel equilibration buffer [50 mM Tris/ $\mathrm{HCl}(\mathrm{pH} 8 \cdot 8), 6 \mathrm{M}$ urea, $30 \%(\mathrm{v} /$ v) glycerol, $2 \%(\mathrm{w} / \mathrm{v})$ SDS and $0.002 \%(\mathrm{w} / \mathrm{v})$ bromophenol blue] containing $100 \mathrm{mg}$ DTT for the first equilibration and $250 \mathrm{mg}$ iodoacetamide for the second equilibration.

SDS-PAGE. Equilibrated isoelectric-focused strips were placed on top of a uniform $14 \%$ SDS-polyacrylamide gel for second-dimension electrophoresis with the Bio-Rad Protean II xi electrophoresis system. Second-dimension separation was carried out at $25 \mathrm{~mA}$ per gel constant current at $4{ }^{\circ} \mathrm{C}$. The gels were stained with Bio-Safe colloidal Coomassie blue G-250 stain according to the manufacturer's (BioRad) instructions.

Analysis of protein spots on 2D-PAGE gels. Individual gels were scanned using an Epson Expression 1680 scanner with a transparency adapter as 8-bit greyscale 300 d.p.i. images. Differentially expressed proteins were then detected and quantified from the images with PDQuest 2-D Analysis Software (Bio-Rad). A twofold difference in expression was set as a threshold during image analysis to detect proteins that were differentially expressed.

Mass spectrometry of proteins. Protein spots of interest were excised from the gel, destained and subjected to in-gel trypsin digestion according to the established protocols for the MassPrep robotic workstation (Water/Micromass). The samples were then dried in a speed-vac and reconstituted in $75 \%$ acetonitrile containing $5 \mathrm{mg}$ $\alpha$-cyano-4-hydroxycinnamic acid $\mathrm{ml}^{-1}$ and eluted directly onto the MALDI plate.

The MALDI-TOF-MS (Voyager DE-STR; Applied Biosystems) was operated in the positive-ion reflectron mode. Four hundred laser shots were averaged and processed with Data Explorer software (Applied Biosystems). The samples were internally calibrated using trypsin autolytic fragments, and database searches carried out with Protein Prospector (UCSF Mass Spectrometry Facility, San Francisco, CA, USA). Sample preparation and MS analysis were performed by the Mass Spectrometry facility at the National Research Council, Plant Biotechnology Institute (Saskatoon, Canada).

\section{RESULTS AND DISCUSSION}

\section{Growth characteristics}

An essential component of genomic or proteomic comparative analysis is the establishment of differentially expressed genes in reference to an appropriate and reproducible control point or growth condition. Bacterial patterns of expression are highly dependent upon growth phase, with dramatic changes accompanying the transition from exponential to stationary-phase growth. As noted by others (Lazazzera, 2005), many of the seemingly contradictory results that have emerged from biofilm expression investigations are due to differences in the growth phase. Careful consideration was therefore given to ensuring comparison of bacteria that were at a common stage of growth stage progression.

The growth curve of $C$. jejuni grown on agar or in broth was determined by plating aliquots from predetermined time points on $\mathrm{MH}$ agar and expressed as c.f.u. per $25 \mathrm{ml}$ medium and c.f.u. $\mathrm{ml}^{-1}$ respectively. As shown in Fig. 1, the growth profiles were very similar for both growth conditions. Cell densities in both growth conditions increased steadily up to $12 \mathrm{~h}$ and maximum cell densities were achieved at $18 \mathrm{~h}$, following which cell death started to occur (Fig. 1). Thus C. jejuni cells at $16 \mathrm{~h}$ of incubation were used in all studies.

\section{Gene and two-dimensional protein expression analysis}

Growth on agar plates. Surface-associated growth of C. jejuni results in a distinct pattern of expression at the levels of transcription and translation relative to growth in broth, with over 90 genes or proteins having altered levels of expression. The results from genomic and proteomic components of this investigation are complementary in that they identify the same functional groupings of biomolecules (Table 1). The absence of a more definitive

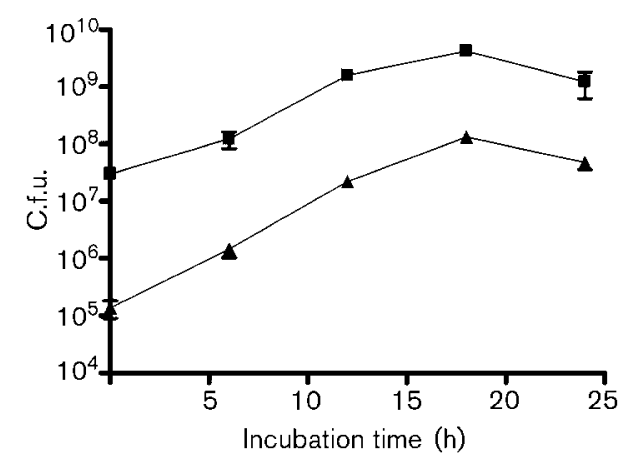

Fig. 1. Growth curves of C. jejuni grown in broth ( $\boldsymbol{\square}$ ) or on agar $(\boldsymbol{\Lambda})$. At the indicated times, samples were removed to determine the viable cell counts present by plating serial dilutions on $\mathrm{MH}$ agar. 
Table 1. Number of quantitative changes, and associated cellular function, identified through proteomic and genomic analysis

\begin{tabular}{|lcc|}
\hline & $\begin{array}{c}\text { Proteomic } \\
\text { analysis }\end{array}$ & $\begin{array}{c}\text { Genomic } \\
\text { analysis }\end{array}$ \\
\hline $\begin{array}{l}\text { Upregulated on agar } \\
\text { Iron metabolism }\end{array}$ & 5 & 3 \\
Oxidative defence & 4 & 3 \\
Energy metabolism & 2 & 7 \\
Protein synthesis & 1 & 13 \\
Membrane modification & 1 & 13 \\
Upregulated in broth & & 3 \\
Energy metabolism & 7 & 29 \\
Motility & & \\
Protein synthesis & & \\
\hline
\end{tabular}

correlation between the genes and proteins identified is likely to be a consequence of post-transcriptional regulatory events.

Many of the proteins found to be induced as a consequence of immobilized growth are membrane-associated and therefore problematic for separation via two-dimensional gel electrophoresis. A proteomic comparison of both total cell protein and detergent-insoluble outer-membrane proteins was performed through one-dimensional SDS-PAGE analysis (Fig. 2). It is of significance that the proteins identified as being differentially expressed as a consequence of growth on agar through one-dimensional SDS-PAGE are in agreement with the results obtained from the twodimensional proteomic analysis (Fig. 3). The nine proteins identified as undergoing differential patterns of expression were also identified within the large-scale proteomic analysis (Tables 2 and 4). An additional detergent-insoluble protein of approximately $27 \mathrm{kDa}$ was uniquely expressed during growth on agar; however this protein could not be positively identified.

\section{Induced systems}

Iron uptake. Bioavailability of iron represents a significant challenge to the survival of bacteria in the environment and during infection of a host. Like most organisms, Campylobacters have an absolute requirement for iron and have adapted iron-acquisition strategies to cope with dynamic patterns of iron availability. Campylobacters have two distinct but overlapping iron-responsive regulatory systems: Fur, which regulates iron-uptake genes, and the Fur homologue, PerR, which regulates oxidative-stress defence (Baillon et al., 1999; Holmes et al., 2005; Palyada et al., 2004; Ratledge \& Dover, 2000; van Vliet et al., 1998). In many species of bacteria Fur is solely responsible for the regulation of iron homeostasis as well as oxidativestress defence. That $C$. jejuni, which contains relatively few regulatory proteins, has evolved two separate systems for iron acquisition and prevention of oxidative damage

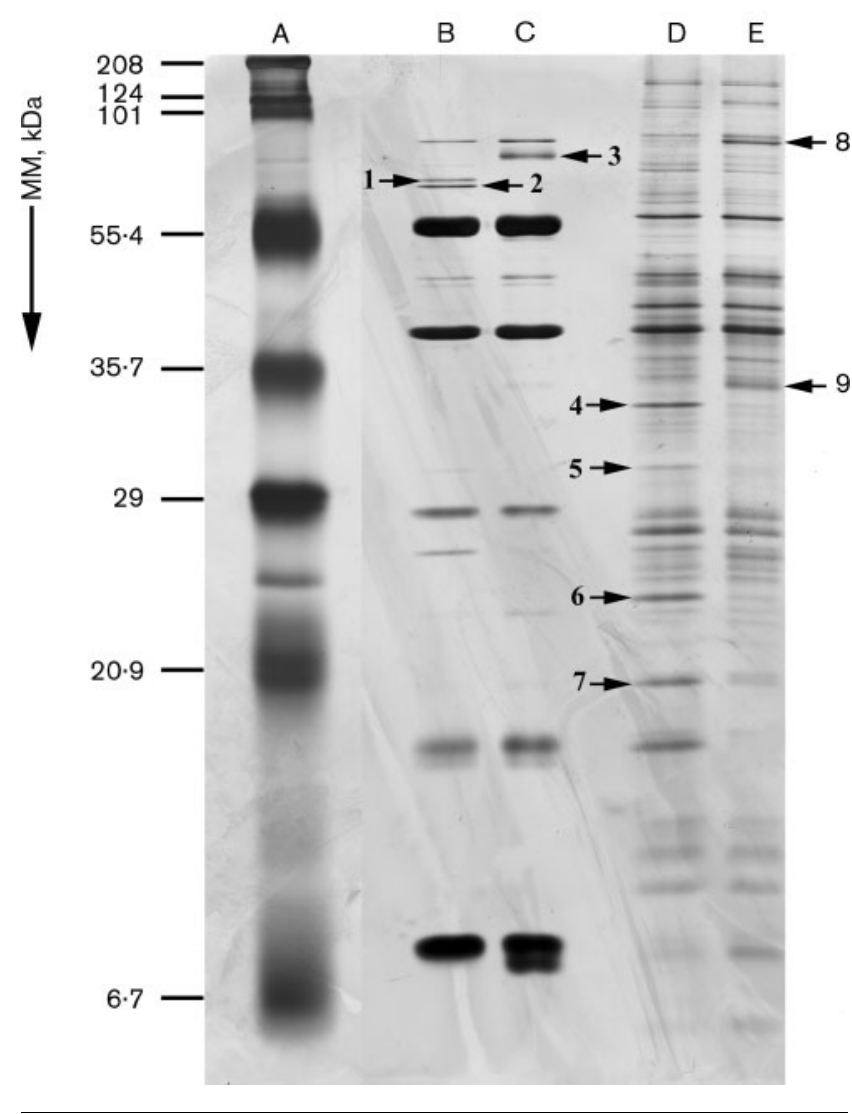

Fig. 2. Silver-stained SDS-PAGE profile of detergent-insoluble and total cellular proteins from C. jejuni NCTC 11168. Proteins identified as being differentially expressed are numbered. Lanes: A, molecular mass markers; $B, C$, detergent-insoluble proteins from growth on agar (B) or broth (C); D, E, total cellular proteins from growth on agar (D) or broth (E).

indicates the central role that iron plays in its gene regulation and virulence.

Both proteomic (Table 2) and microarray data (Table 3) demonstrate significant upregulation of genes and proteins with involvement in iron acquisition. These include ChuA, a haemin/haemoglobin uptake system (Cj1614), a possible outer membrane siderophore receptor (Cj0178), components of putative iron-uptake $\mathrm{ABC}$ transport systems (Cj0175c, Cj0174c and Cj1663), cfrA, a putative iron-uptake protein (Cj0755) and the periplasmic protein p19 (Cj1659). The induction of iron-uptake molecules, at the levels of both transcription and translation, as a consequence of growth on agar represents the most dramatic alteration in expression; at the level of transcription the three most strongly induced genes code for iron-uptake proteins (Table 3 ) and a parallel pattern is seen at the level of translation with the unique or highly induced expression of several iron-uptake proteins (Figs 3 and 4).

From the perspective of immobilized growth, rather than growth in broth, representing the most physiologically 
(a)

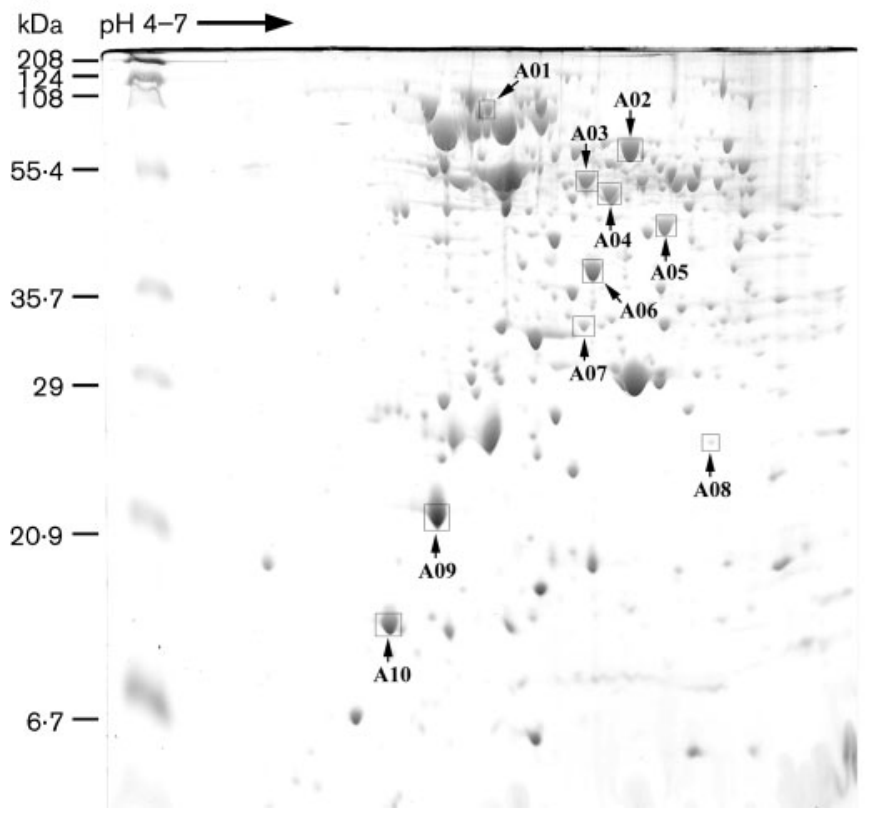

(b)

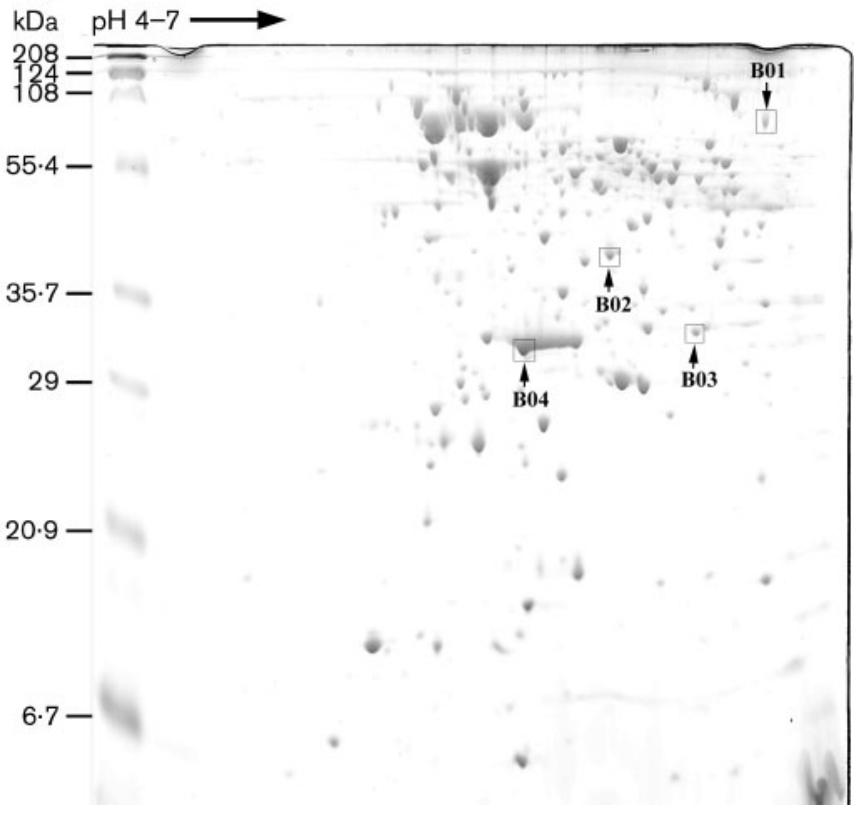

Fig. 3. Protein expression profiles of C. jejuni NCTC 11168 grown on $\mathrm{MH}$ agar (a) or in $\mathrm{MH}$ broth (b). Labelled spots indicate those identified as being either uniquely or strongly induced under the growth condition. Spots whose number is prefixed with ' $A$ ' are induced during growth on agar; those prefixed with ' $B$ ' are induced during growth in broth.

appropriate baseline, the induction of iron-uptake systems during surface-associated growth may be more appropriately viewed as a repression of these systems during growth in liquid media.

The increased requirement for iron during immobilized growth, whether within a biofilm or surface-associated growth, is probably a consequence of the increased cell densities depleting locally available iron stores. These iron-uptake systems show a similar pattern of induction for C. jejuni under iron-limiting conditions (Holmes et al., 2005), as well as during growth within a host (Stintzi et al., 2005).

Induction of iron-uptake systems has not emerged as a conserved response within investigations of biofilms, although it has been reported for select biofilms (Pysz et al., 2004). The availability of iron does however represent a central

Table 2. Proteins induced during growth of C. jejuni NCTC 11168 on MH agar

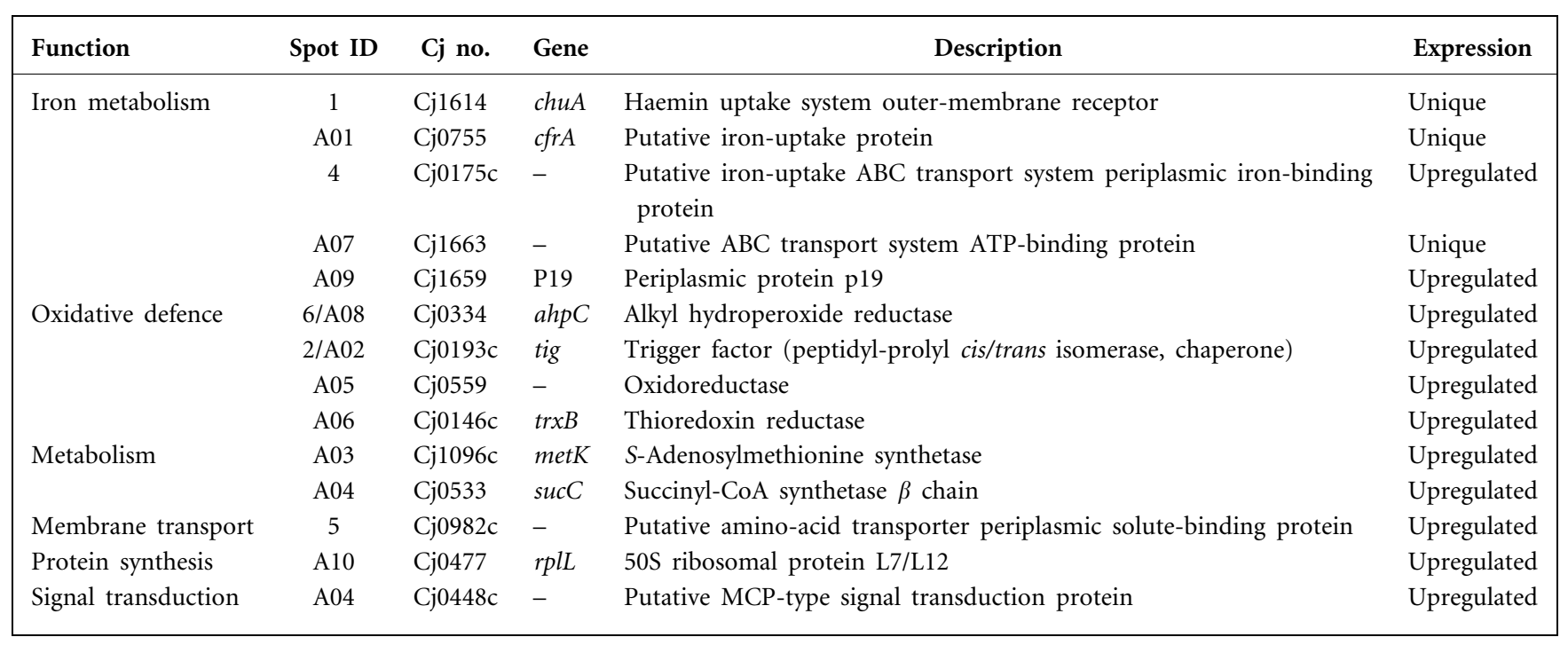


Table 3. Genes induced during growth of C. jejuni NCTC 11168 on MH agar

\begin{tabular}{|c|c|c|c|c|c|c|}
\hline Function & $\mathrm{Cj}$ no. & Gene & Description & $\begin{array}{c}\log \\
\text { (Mean ratio) }\end{array}$ & $Z$-score & $\begin{array}{c}P \\
\text { (2-tailed) }\end{array}$ \\
\hline \multirow[t]{3}{*}{ Iron uptake } & $\mathrm{Cj} 0174 \mathrm{c}$ & - & Putative iron-uptake $\mathrm{ABC}$ transport system permease protein & $0 \cdot 258$ & $8 \cdot 13$ & $4 \cdot 44 \mathrm{E}-16$ \\
\hline & Cj1614 & chuA & Haemin uptake system outer-membrane receptor & $1 \cdot 012$ & $24 \cdot 13$ & 0 \\
\hline & $\mathrm{Cj} 0178$ & - & Putative outer-membrane siderophore receptor & $0 \cdot 876$ & $20 \cdot 90$ & 0 \\
\hline \multirow[t]{3}{*}{ Oxidative defence } & Cj1385 & katA & Catalase & $1 \cdot 096$ & $26 \cdot 14$ & 0 \\
\hline & Cj0393c & - & Putative oxidoreductase & $0 \cdot 176$ & $5 \cdot 55$ & $2 \cdot 82 \mathrm{E}-08$ \\
\hline & $\mathrm{Cj} 1287 \mathrm{c}$ & - & Malate oxidoreductase & $0 \cdot 227$ & $7 \cdot 16$ & $8 \cdot 28 \mathrm{E}-13$ \\
\hline \multirow[t]{5}{*}{ Metabolism } & Cj0347 & $\operatorname{trpF}$ & $N$-(5'-Phosphoribosyl)anthranilate isomerase & $0 \cdot 191$ & $6 \cdot 03$ & $1 \cdot 61 \mathrm{E}-09$ \\
\hline & Cj0348 & $\operatorname{trp} B$ & Tryptophan synthase $\beta$ chain & $0 \cdot 329$ & $10 \cdot 39$ & 0 \\
\hline & Cj0689 & ackA & Acetate kinase & $0 \cdot 184$ & $5 \cdot 81$ & $6 \cdot 16 \mathrm{E}-09$ \\
\hline & Cj0483 & $u x a A^{\prime}$ & Putative altronate hydrolase C-terminus & $0 \cdot 244$ & $7 \cdot 69$ & $1 \cdot 53 \mathrm{E}-14$ \\
\hline & Cj0346 & $\operatorname{trpD}$ & Anthranilate synthase component II & $0 \cdot 178$ & $5 \cdot 63$ & $1 \cdot 79 \mathrm{E}-08$ \\
\hline \multirow[t]{3}{*}{ Membrane } & Cj0811 & $\operatorname{lp} x K$ & Putative tetraacyldisaccharide $4^{\prime}$-kinase & $0 \cdot 180$ & $5 \cdot 25$ & $1 \cdot 49 \mathrm{E}-07$ \\
\hline & Cj1151c & $w a a D$ & ADP-L-glycero-D-manno-heptose-6-epimerase & $0 \cdot 271$ & $7 \cdot 93$ & $2 \cdot 22 \mathrm{E}-15$ \\
\hline & Cj1133 & $w a a C$ & Putative lipopolysaccharide heptosyltransferase & $0 \cdot 410$ & $12 \cdot 95$ & 0 \\
\hline \multirow[t]{10}{*}{ Transport systems } & Cj0922c & pebC & ABC-type amino-acid transporter ATP-binding protein & $0 \cdot 185$ & $5 \cdot 42$ & $6 \cdot 03 \mathrm{E}-08$ \\
\hline & Cj0613 & pst $S$ & Possible periplasmic phosphate-binding protein & $0 \cdot 184$ & $5 \cdot 38$ & $7 \cdot 52 \mathrm{E}-08$ \\
\hline & Cj0920c & - & Putative ABC-type amino-acid transporter permease protein & $0 \cdot 283$ & $6 \cdot 16$ & $7 \cdot 26 \mathrm{E}-10$ \\
\hline & $\mathrm{Cj} 0300 \mathrm{c}$ & $\bmod C$ & Putative molybdenum-transport ATP-binding protein & $0 \cdot 255$ & $8 \cdot 03$ & $8 \cdot 88 \mathrm{E}-16$ \\
\hline & Cj0919c & - & Putative ABC-type amino-acid transporter permease protein & $0 \cdot 283$ & $7 \cdot 54$ & $4 \cdot 64 \mathrm{E}-14$ \\
\hline & Cj0303c & $\bmod A$ & Putative molybdate-binding lipoprotein & $0 \cdot 298$ & $8 \cdot 70$ & 0 \\
\hline & Cj0730 & - & Putative $\mathrm{ABC}$ transport system permease & $0 \cdot 409$ & $9 \cdot 76$ & 0 \\
\hline & Cj0982c & - & $\begin{array}{l}\text { Putative amino-acid transporter periplasmic solute-binding } \\
\text { protein }\end{array}$ & $0 \cdot 714$ & $14 \cdot 74$ & 0 \\
\hline & Cj1163c & - & Putative cation-transport protein & $0 \cdot 216$ & $6 \cdot 80$ & $1 \cdot 03 \mathrm{E}-11$ \\
\hline & $\mathrm{Cj} 1502 \mathrm{c}$ & putP & Sodium/proline symporter & $0 \cdot 508$ & $16 \cdot 03$ & 0 \\
\hline
\end{tabular}

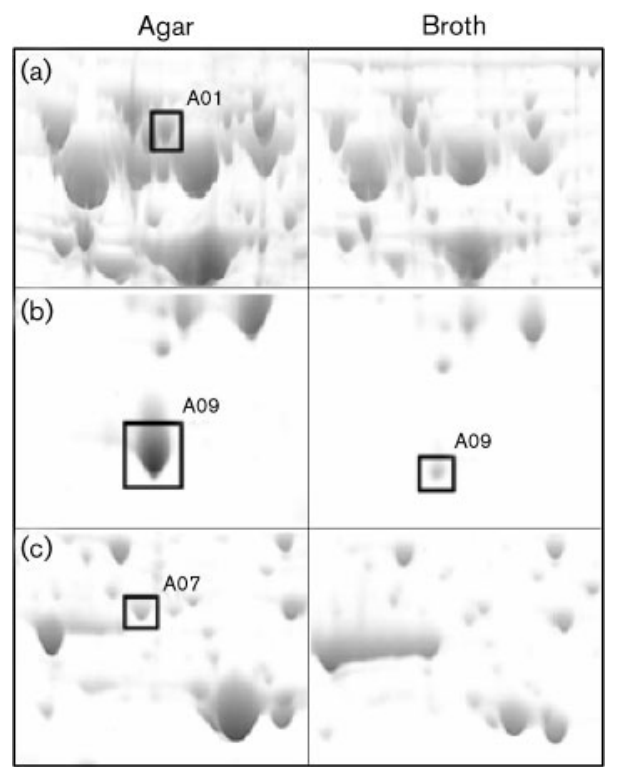

Fig. 4. Proteins induced as a consequence of immobilized growth of C. jejuni NCTC 11168 on $\mathrm{MH}$ agar: (a) ferric receptor (A01), (b) $19 \mathrm{kDa}$ periplasmic protein (A09) and (c) putative ABC transport system ATP-binding protein (A07). consideration in the decision to commit to biofilm formation; iron chelation through lactoferrin has been shown to discourage Pseudomonas aeruginosa biofilm formation. The repression of biofilm formation is hypothesized to occur due to the insufficient iron responses to match the localized increases in demand for iron by biofilm bacteria. This appears to be a general phenomenon, with the adhesion of various species of bacteria to biomaterials being suppressed by iron chelators at concentrations which are unable to influence growth in the vegetative state (Ardehali et al., 2002).

Oxidative defence. In addition to representing a limiting nutrient to bacterial survival, iron imposes an additional challenge to living systems through its involvement in the generation of toxic molecules. Iron can react with oxygen to produce reactive oxygen species like superoxide anions $\left(\mathrm{O}_{2}^{-}\right)$, peroxides $\left(\mathrm{RO}_{2}\right)$ and hydroxyl radicals $\left(\mathrm{OH}^{-}\right)$ through the Haber-Weiss $\left(\mathrm{Fe}_{2}^{+}+\mathrm{O}_{2} \rightarrow \mathrm{Fe}_{3}^{+}+\mathrm{O}_{2}^{-}\right)$and Fenton $\left(\mathrm{Fe}_{2}^{+}+\mathrm{H}_{2} \mathrm{O}_{2} \rightarrow \mathrm{Fe}_{3}^{+}+\mathrm{OH}^{-}+\mathrm{OH}^{*}\right)$ reactions. The absolute requirement for iron for electron transport of microaerophilic organisms like $C$. jejuni therefore requires the bacteria to maintain a proper iron homeostasis and to coordinate expression of iron-uptake and oxidative stress systems. In contrast to other Gram-negative bacteria, oxidative stress and iron acquisition are regulated separately in C. jejuni (van Vliet et al., 1998). This is of 
Table 4. Proteins induced during growth of C. jejuni NCTC 11168 in MH broth

These proteins all function in energy metabolism.

\begin{tabular}{|lllll|}
\hline Spot ID & Cj no. & Gene & \multicolumn{1}{c|}{ Description } & Expression \\
\hline 3 & Cj0264c & - & Molybdopterin-containing oxidoreductase & Unique \\
8 & Cj0780 & $n a p A$ & Periplasmic nitrate reductase & Upregulated \\
B01 & Cj0437 & $s d h A$ & Succinate dehydrogenase flavoprotein subunit & Unique \\
B02 & Cj1267c & $h y d A$ & Ni/Fe-hydrogenase small chain & Upregulated \\
B03 & Cj1510c & $f d h B$ & Putative formate dehydrogenase iron-sulfur subunit & Upregulated \\
B04 & Cj0012c & - & Non-haem iron protein & Upregulated \\
9 & Cj0358 & - & Putative cytochrome $c_{551}$ peroxidase & Upregulated \\
\hline
\end{tabular}

particular significance given the limited number of regulatory systems present within the bacteria.

Oxidative stress proteins often show distinct patterns of induction in response to different kinds of oxidative stress: superoxide stress and peroxide stress. The superoxide stress proteins include manganese-containing superoxide dismutase and endonuclease IV; the peroxide regulon contains catalase (KatA) and alkyl hydroperoxide reductase (AhpC). The regulation of AhpC and KatA expression in C. jejuni has a Fur-independent component, as the expression of these proteins is only partially affected by the mutation of Fur. A second Fur homologue, the peroxide stress regulator PerR, functions to co-regulate $a h p C$ and katA expression (van Vliet et al., 1998).

Parallel to the observation that iron functions as both a signal and an ongoing challenge for formation and survival within a biofilm, oxidative stress also appears to serve as both a trigger and a required adaptive response for biofilm formation and survival. Biofilm formation has been observed in response to oxidative stress in the hyperthermophilic archaeon Archaeoglobus fulgidus (LaPaglia \& Hartzell, 1997) and certain aerobic mesophilic biofilms showed increased expression of oxidative stress genes (Golovlev, 2002; Schembri et al., 2003).

As a consequence of growth on agar there was increased expression of the primary oxidative stress defence components, alkyl hydroperoxide reductase $(a h p C)$ and catalase $(k a t A)$. Increased expression of additional proteins with known involvement in the minimization of oxidative damage, including oxidoreductase (Cj0559), a putative oxidoreductase (Cj0393c) and malate oxidoreductase $(\mathrm{Cj} 1287 \mathrm{c})$, was also observed. The ribosomally associated stress response chaperone, trigger factor (Cj0193c), which has also been implicated in oxidative stress response, exhibited increased expression (Tables 2 and 3 ).

Membrane modification. Our characterization of sessile C. jejuni indicates the upregulation of enzymes involved in modifications of the lipid, carbohydrate and protein components of the membrane. These include the upregulation of ADP-L-glycero-D-manno-heptose-6-epimerase (waaD), as well as two putative membrane-modification enzymes, tetraacyldisaccharide $4^{\prime}$-kinase $(l p x K)$ and lipopolysaccharide heptosyltransferase (waaC) (Table 3). Notably, our analysis does not reveal the induction of a large number of the enzymes with established roles in the formation of the biofilm-associated extracellular matrix, supportive of growth on agar as a model of mid-to-late-phase biofilm formation.

ABC transport systems. Many of the membrane proteins that undergo differential expression as a consequence of growth on agar are associated with the primary active transport of amino acids. To our knowledge there have been no previous connections proposed between either low-iron adaptation or biofilm formation and amino acid transport and metabolism, although amino acid starvation was identified as a trigger for biofilm formation for Candida albicans (Garcia-Sanchez et al., 2004). The induction of $A B C$ transport systems which are not specific to amino acid transport has been reported as a consequence of biofilm formation (Pysz et al., 2004) although the functional relevance remains unclear.

As many of the induced transporters identified in our investigation are $\mathrm{ABC}$-type primary active-transport systems one possibility is that they may have roles in mediating the efflux of antibiotics and antimicrobial agents such that the induction of these systems may be related to the increased resistance to antibiotics which is a hallmark of biofilm bacteria. While the sheltering of bacteria within the biofilm extracellular matrix may provide the initial line of defence against antibiotics this may be supplemented through the ability to actively transport antibiotics out of the bacteria.

Other transport systems. In addition to the $\mathrm{ABC}$ transport systems, growth on agar also resulted in the induction of both phosphate and molybdate-transport systems (Table 3).

The induction of molydbate uptake systems, and corresponding repression of molydbate-requiring enzymes such as periplasmic nitrate reductase, has been reported from investigations of C. jejuni in iron-limiting conditions (Holmes et al., 2005; Palyada et al., 2004). This parallels our observation of induction of a putative molybdenum-transport 
ATP-binding protein, a molybdate-binding lipoprotein and a periplasmic phosphate-binding protein, as well as the repression of periplasmic nitrate reductase and molybdopterin oxidoreductase under sessile growth conditions. Molybdate metabolism appears to be closely coordinated with that of iron, so the patterns of expression we observe may be a secondary consequence of iron limitation during immobilized growth.

\section{Systems repressed during growth on agar}

Growth on agar results in the repression of a variety of cellular systems as determined by their induction during growth in broth. The overall objectives represented by these systems indicate a trend towards a reduction in metabolism, motility and protein synthesis. There is also a general repression of non-essential, iron-containing enzymes, presumably as a measure to conserve iron for essential processes.

Non-essential iron-containing proteins. Levels of several non-essential iron-containing proteins were decreased in iron-limiting conditions at the levels of transcription (Table 5) and translation (Table 4). For example, nonhaem protein (Cj0012c), Ni/Fe hydrogenase $(\mathrm{Cj} 1267 \mathrm{c})$, ferredoxin, cytochrome $c$ peroxidase and a member of the succinate dehydrogenase complex (Cj0437) all show decreased levels of expression. The alterations in levels of expression of these proteins were some of the most dramatically observed at the level of translation (Fig. 5). The pattern of genes induced in broth bears close resemblance to those reported to be induced upon the addition of iron to $C$. jejuni which have been cultured in ironlimited media (Holmes et al., 2005; Palyada et al., 2004).

Energy metabolism. Growth on agar results in the repression of genes involved in metabolic processes, in particular respiratory and iron-containing enzymes (Tables 4 and $5)$. This probably serves a dual function in conservation of bioavailable iron, as well as in the minimization of reactive by-products of oxidative metabolism. This is consistent with patterns of expression reported by others under low-iron conditions.

Motility. The repression of genes involved in motility is a logical consequence of an immobilized growth state and has been observed during biofilm formation for both $P$. aeruginosa (Whitely et al., 2001) and Bacillus subtilis (Stanley et al., 2003). In our investigation we report the repression of flagellin (FlaB), the flagellar biosynthesis protein (FlhA) and a putative RNA polymerase sigma factor for the flagellar operon (FliA) in the sessile state (Tables 4 and 5). The repression of biomolecules involved in motility would function to conserve the significant energy expenditure associated with flagella production, consistent with the general downregulation of energy-production systems observed during immobilized growth.

While the repression of motility genes during immobilized growth is consistent with the majority of biofilm expression studies, this has not been a unanimous conclusion. Indeed some groups have reported the induction of motility biomolecules during biofilm formation. There are suggestions however that the lack of repression of motility systems

Table 5. Genes induced during growth of C. jejuni NCTC 11168 in $\mathrm{MH}$ broth

\begin{tabular}{|c|c|c|c|c|c|c|}
\hline Function & $\mathrm{Cj}$ no. & Gene & Description & $\log ($ Mean ratio $)$ & $Z$-score & $P$ (2-tailed) \\
\hline \multirow{5}{*}{$\begin{array}{l}\text { Oxidative } \\
\text { phosphorylation }\end{array}$} & $\mathrm{Cj} 1489 \mathrm{c}$ & $\operatorname{ccoO}$ & $c b$-type cytochrome $c$ oxidase subunit II & $-0 \cdot 183$ & $-5 \cdot 79$ & $6 \cdot 97 \mathrm{E}-09$ \\
\hline & Cj1488c & $\operatorname{cco} Q$ & $c b$-type cytochrome $c$ oxidase subunit IV & $-0 \cdot 231$ & $-7 \cdot 28$ & $3 \cdot 24 \mathrm{E}-13$ \\
\hline & Cj1185c & $\operatorname{pet} B$ & $\begin{array}{l}\text { Putative ubiquinol-cytochrome } c \text { reductase } \\
\text { cytochrome } b \text { subunit }\end{array}$ & $-0 \cdot 488$ & $-11 \cdot 65$ & 0 \\
\hline & $\mathrm{Cj} 1184 \mathrm{c}$ & petC & $\begin{array}{l}\text { Putative ubiquinol-cytochrome } c \text { reductase } \\
\text { cytochrome } c \text { subunit }\end{array}$ & $-0 \cdot 279$ & $-8 \cdot 15$ & $4 \cdot 44 \mathrm{E}-16$ \\
\hline & Cj0102 & $\operatorname{atp} F^{\prime}$ & ATP synthase $F_{0}$ sector $B^{\prime}$ subunit & $-0 \cdot 241$ & $-7 \cdot 05$ & $1 \cdot 77 \mathrm{E}-12$ \\
\hline \multirow[t]{4}{*}{ Nitrogen metabolism } & Cj0780 & napA & Periplasmic nitrate reductase & $-0 \cdot 291$ & $-8 \cdot 49$ & 0 \\
\hline & Cj0783 & $n a p B$ & $\begin{array}{l}\text { Periplasmic nitrate reductase small subunit } \\
\text { (cytochrome } c \text {-type protein) }\end{array}$ & $-0 \cdot 298$ & $-8 \cdot 70$ & 0 \\
\hline & Cj0781 & $n a p G$ & Putative ferredoxin & $-0 \cdot 363$ & $-11 \cdot 46$ & 0 \\
\hline & Cj0782 & $n a p H$ & Putative ferredoxin & $-0 \cdot 195$ & $-4 \cdot 03$ & $5 \cdot 65 \mathrm{E}-05$ \\
\hline Energy metabolism & Cj1511c & $f d h A$ & $\begin{array}{l}\text { Putative formate dehydrogenase large subunit } \\
\text { (selenocysteine containing) }\end{array}$ & $-0 \cdot 198$ & $-5 \cdot 78$ & $7 \cdot 60 \mathrm{E}-09$ \\
\hline \multirow[t]{3}{*}{ Motility } & $\mathrm{Cj} 1338 \mathrm{c}$ & $f l a B$ & Flagellin & $-0 \cdot 205$ & $-6 \cdot 48$ & $9 \cdot 05 \mathrm{E}-11$ \\
\hline & Cj0882c & flhA & Flagellar biosynthesis protein & $-0 \cdot 183$ & $-5 \cdot 36$ & $8 \cdot 53 \mathrm{E}-08$ \\
\hline & Cj0061c & fliA & $\begin{array}{l}\text { Putative RNA polymerase sigma factor for } \\
\text { flagellar operon (sigma- } 28 \text { factor) }\end{array}$ & $-0 \cdot 527$ & $-12 \cdot 57$ & 0 \\
\hline
\end{tabular}




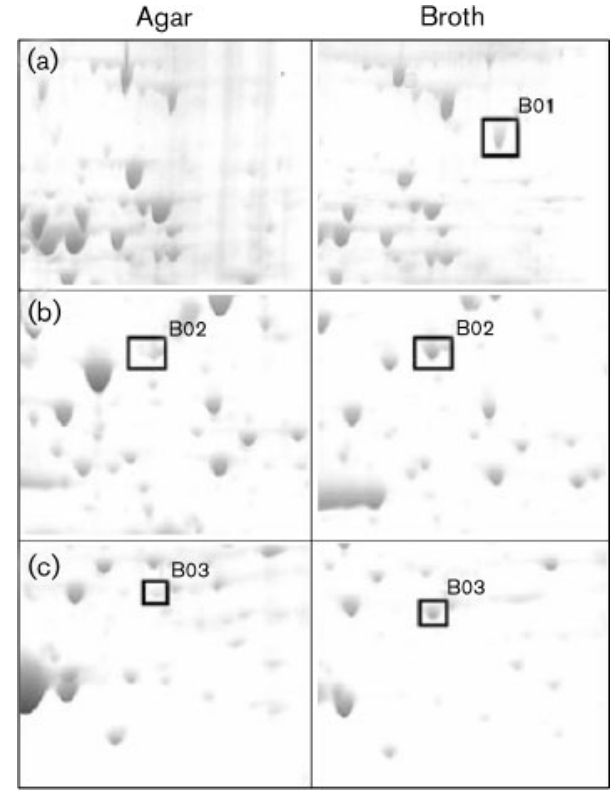

Fig. 5. Proteins induced as a consequence of growth of $C$. jejuni NCTC 11168 in $\mathrm{MH}$ broth: (a) succinate dehydrogenase flavoprotein subunit (B01), (b) Ni/Fe hydrogenase small chain (B02) and (c) putative formate dehydrogenase iron-sulfur subunit (B03).

in these investigations reflects differences in experimental design rather than discrepancies in biological response. For studies of $B$. subtilis biofilms, in which one of the two investigations observed repression of flagellar genes, the biofilms were grown in similar conditions; however, the planktonic cells were not (Ren et al., 2004a; Stanley et al., 2003). Similarly, investigations of Escherichia coli biofilms that did not observe repression of motility genes through microarray analysis (Beloin \& Ghigo, 2005; Ren et al., 2004b; Schembri et al., 2003) did show repression when assayed with a $l a c Z$ transcriptional fusion (PrigentCombaret et al., 1999). Thus, repression of genes involved in motility probably represents a conserved theme amongst biofilms.

Ribosomal synthesis. Repression of ribosomal proteins during immobilized growth emerges as one of the most definitive conclusions from our investigations, with 30 of the 53 ribosomal proteins identified as being repressed (Table 6). This is consistent with the overall trend of adaptation in the sessile state towards a dormant lifestyle with reduced energy production and expenditure.

Amongst biofilm investigations the levels of expression of ribosomal proteins are an interesting point of contention, with equal but contradicting opinions of whether these proteins are induced or repressed. These contradictory findings are probably a consequence of the growth phase of the planktonic cells to which biofilm cells are compared.
This is best exemplified by a study of E. coli biofilms which identified ribosomal proteins as being more highly expressed in biofilm cells when compared with stationaryphase cells, but not when compared with exponential-phase planktonic cells (Schembri et al., 2003). The suggestion that the expression of ribosomal proteins is activated in biofilms is surprising as this presumably reflects increased growth rate.

\section{Conclusions}

While growth within the permissive conditions of liquid media is often taken as the reference point of bacterial behaviour these conditions do not reflect the challenges encountered by bacteria in the natural environment. There is considerable evidence that bacteria spend a significant portion of their natural existence in an immobilized state through the formation of microcolonies and biofilms. The cellular adaptations that accompany survival in a sedentary state are therefore of significant biological interest. For pathogenic bacteria, such as $C$. jejuni, immobilization takes on further significance as it represents a prerequisite step to the formation of biofilms, as well as in the establishment of the early stages of virulence. Growth on agar is proposed to function as a limited model of a developmental stage towards each of these phenotypes.

Through genomic and proteomic analysis we have established expression profiles for $C$. jejuni during immobilized and planktonic growth. Relative to growth in broth, growth on agar results in the induction of systems directed towards the biological objectives of iron acquisition, management of oxidative stress and modifications to both the lipid and protein composition of the membranes. During growth on agar there is a corresponding repression of systems involved in energy production, motility and protein synthesis, in particular of non-essential iron-requiring proteins.

The ability of a single growth condition to function as a model for two distinct phenotypes is a consequence of the common denominator within each of these processes in the requirement for an immobilized growth state. This is consistent with the emerging hypothesis that specific bacterial phenotypes do not result from the expression of phenotype-specific genes but rather from the expression of particular subsets of genes that can be induced under a variety of conditions (Lazazzera, 2005).

Food-borne pathogenic bacteria such as $C$. jejuni can experience rapid transitions from a relatively dormant phase of environmental survival to life within a host. This transition is associated with dramatic shifts in nutrient availability as well as host immune defences. The systems induced during surface-associated growth bestow a phenotype that facilitates survival both within the environment, as well as upon encountering the host, through the prioritizing of systems to withstand two of the most significant challenges associated with the host: iron limitation and oxidative stress. 
Table 6. Ribosomal genes induced during growth of C. jejuni NCTC 11168 in MH broth

\begin{tabular}{|c|c|c|c|c|c|}
\hline Cj no. & Gene & Description $^{\star}$ & $\log ($ Mean ratio $)$ & Z-score & $P$ (2-tailed) \\
\hline Cj1704c & rplB & 50S RP L2 & $-0 \cdot 262$ & $-8 \cdot 26$ & $2 \cdot 22 \mathrm{E}-16$ \\
\hline $\mathrm{Cj} 1707 \mathrm{c}$ & $r p l C$ & 50S RP L3 & $-0 \cdot 214$ & $-6 \cdot 75$ & $1 \cdot 50 \mathrm{E}-11$ \\
\hline Cj1706c & $r p l D$ & 50S RP L4 & $-0 \cdot 201$ & $-5 \cdot 87$ & $4 \cdot 41 \mathrm{E}-09$ \\
\hline Cj0476 & rplJ & 50S RP L10 & $-0 \cdot 250$ & $-7 \cdot 90$ & $2 \cdot 66 \mathrm{E}-15$ \\
\hline Cj1480c & rplM & 50S RP L13 & $-0 \cdot 187$ & $-5 \cdot 91$ & $3 \cdot 48 \mathrm{E}-09$ \\
\hline Cj1689c & rplO & 50S RP L15 & $-0 \cdot 198$ & $-5 \cdot 79$ & $7 \cdot 16 \mathrm{E}-09$ \\
\hline Cj1700c & $r p l P$ & 50S RP L16 & $-0 \cdot 208$ & $-6 \cdot 56$ & $5 \cdot 44 \mathrm{E}-11$ \\
\hline Cj1691c & $r p l R$ & 50S RP L18 & $-0 \cdot 214$ & $-6 \cdot 75$ & $1 \cdot 49 \mathrm{E}-11$ \\
\hline Cj0245 & rplT & 50S RP L20 & $-0 \cdot 204$ & $-6 \cdot 45$ & $1 \cdot 13 \mathrm{E}-10$ \\
\hline $\mathrm{Cj} 1702 \mathrm{c}$ & $r p l V$ & 50S RP L22 & $-0 \cdot 207$ & $-6 \cdot 54$ & $6 \cdot 09 \mathrm{E}-11$ \\
\hline Cj1705c & $r p l W$ & 50S RP L23 & $-0 \cdot 203$ & $-6 \cdot 42$ & $1 \cdot 36 \mathrm{E}-10$ \\
\hline Cj1696c & $r p l X$ & 50S RP L24 & $-0 \cdot 205$ & $-6 \cdot 46$ & $1 \cdot 02 \mathrm{E}-10$ \\
\hline $\mathrm{Cj1699c}$ & $r p m C$ & 50S RP L29 & $-0 \cdot 230$ & $-7 \cdot 24$ & $4 \cdot 41 \mathrm{E}-13$ \\
\hline Cj0330c & $r p m F$ & 50S RP L32 & $-0 \cdot 329$ & $-9 \cdot 62$ & 0 \\
\hline Cj0244 & rpmI & 50s RP L35 & $-0 \cdot 272$ & $-8 \cdot 59$ & 0 \\
\hline Cj1591 & rpmJ & 50S RP L36 & $-0 \cdot 241$ & $-7 \cdot 03$ & $2 \cdot 06 \mathrm{E}-12$ \\
\hline $\mathrm{Cj} 1182 \mathrm{c}$ & $r p s B$ & 30S RP S2 & $-0 \cdot 243$ & $-7 \cdot 66$ & $1 \cdot 82 \mathrm{E}-14$ \\
\hline Cj1701c & $r p s C$ & $30 \mathrm{~S}$ RP S3 & $-0 \cdot 256$ & $-8 \cdot 09$ & $6 \cdot 66 \mathrm{E}-16$ \\
\hline Cj1594 & $r p s D$ & 30S RP S4 & $-0 \cdot 262$ & $-8 \cdot 27$ & $2 \cdot 22 \mathrm{E}-16$ \\
\hline Cj1070 & $r p s F$ & 30S RP S6 & $-0 \cdot 197$ & $-6 \cdot 20$ & $5 \cdot 63 \mathrm{E}-10$ \\
\hline Cj1693c & $r p s H$ & 30S RP S8 & $-0 \cdot 266$ & $-7 \cdot 77$ & $7 \cdot 77 \mathrm{E}-15$ \\
\hline Cj1708c & rpsJ & $30 \mathrm{~S}$ RP S10 & $-0 \cdot 238$ & $-6 \cdot 94$ & $3 \cdot 97 \mathrm{E}-12$ \\
\hline Cj1593 & $r p s K$ & 30S RP S11 & $-0 \cdot 304$ & $-9 \cdot 58$ & 0 \\
\hline Cj1592 & $r p s M$ & 30S RP S13 & -0.333 & $-10 \cdot 51$ & 0 \\
\hline Cj1694c & $r p s N$ & 30S RP S14 & $-0 \cdot 211$ & $-6 \cdot 65$ & $2 \cdot 86 \mathrm{E}-11$ \\
\hline Cj1698c & $\operatorname{rps} Q$ & 30S RP S17 & $-0 \cdot 228$ & $-7 \cdot 18$ & $6 \cdot 87 \mathrm{E}-13$ \\
\hline Cj1072 & $r p s R$ & 30S RP S18 & $-0 \cdot 181$ & $-5 \cdot 72$ & $1 \cdot 05 \mathrm{E}-08$ \\
\hline $\mathrm{Cj} 1703 \mathrm{c}$ & rpsS & 30S RP S19 & $-0 \cdot 237$ & $-7 \cdot 47$ & $8 \cdot 17 \mathrm{E}-14$ \\
\hline Cj1611 & $r p s T$ & 30S RP S20 & $-0 \cdot 204$ & $-6 \cdot 45$ & $1 \cdot 12 \mathrm{E}-10$ \\
\hline
\end{tabular}

${ }^{\star} \mathrm{RP}$, ribosomal protein.

\section{ACKNOWLEDGEMENTS}

This work was supported by Genome Prairie, Genome BC and Inimex Pharmaceuticals through the 'Functional Pathogenomics of Mucosal Immunity' project as well as through funding from the Canadian Bacterial Diseases Network (CBDN) and the National Research Council's Genome and Health Initiative. L.A. B. is a holder of the Canada Research Chair in Vaccinology and A. A. P. is a holder of the NSERC/Bioniche Industrial Research Chair in Food Safety. DNA microarray hybridizations were performed by Oksana Mykytczuk.

Published with permission of the Director of VIDO as manuscript no. 411.

\section{REFERENCES}

Altekruse, S. F., Stern, N. J., Fields, P. I. \& Swerdlow, D. L. (1999). Campylobacter jejuni - an emerging foodborne pathogen. Emerg Infect Dis 5, 28-35.

Ardehali, R., Shi, L., Janatova, J., Mohammad, S. F. \& Burns, G. L. (2002). The effect of apo-transferrin on bacterial adhesion to biomaterials. Artif Organs 26, 512-520.
Baillon, M. L., van Vliet, A. H., Ketley, J. M., Constantinidou, C. \& Penn, C. W. (1999). An iron-regulated alkyl hydroperoxide reductase (AhpC) confers aerotolerance and oxidative stress resistance to the microaerophilic pathogen Campylobacter jejuni. J Bacteriol 181, 4798-4804.

Beloin, C. \& Ghigo, J. M. (2005). Finding gene-expression patterns in bacterial biofilms. Trends Microbiol 13, 16-19.

Berndtson, E., Danielsson-Tham, M. L. \& Engvall, A. (1996). Campylobacter incidence on a chicken farm and the spread of Campylobacter during the slaughter process. Int J Food Microbiol 32, 35-47.

Bolton, F. J., Coates, D., Hutchinson, D. N. \& Godfree, A. F. (1987). A study of thermophilic campylobacters in a river system. J Appl Bacteriol 62, 167-176.

Bradford, M. M. (1976). A rapid and sensitive method for the quantification of microgram quantities of protein utilizing the principle of protein-dye binding. Anal Biochem 72, 248-254.

Carrillo, C. D., Taboada, E., Nash, J. H. E. \& 15 other authors (2004). Genome-wide expression analyses of Campylobacter jejuni NCTC 11168 reveals coordinate regulation of motility and virulence by flhA. J Biol Chem 279, 20327-20338. 
de Melo, M. A. \& Pechere, J. C. (1990). Identification of Campylobacter jejuni surface proteins that bind to eucaryotic cells in vitro. Infect Immun 58, 1749-1756.

Garcia-Sanchez, S., Aubert, S., Iraqui, I., Janbon, G., Ghigo, J. M. \& d'Enfert, C. (2004). Candida albicans biofilms: a developmental state associated with specific and stable gene expression patterns. Eukaryot Cell 3, 536-545.

Golovlev, E. L. (2002). The mechanism of formation of Pseudomonas aeruginosa biofilm, a type of structured population. Microbiology 71, 249-254.

Görg, A., Obermaier, C., Boguth, G., Harder, A., Scheibe, B., Wildgruber, R. \& Weiss, W. (2000). The current state of twodimensional electrophoresis with immobilized $\mathrm{pH}$ gradients. Electrophoresis 6, 1037-1053.

Holmes, K., Mulholland, F., Pearson, B. M., Pin, C., McNicholKennedy, J., Ketely, J. M. \& Wells, J. M. (2005). Campylobacter jejuni gene expression in response to iron limitation and the role of Fur. Microbiology 151, 243-257.

Jones, K. (2001). The Campylobacter conundrum. Trends Microbiol 9, 365-366.

Jones, K. \& Bradshaw, S. B. (1996). Biofilm formation by Enterobacteriaceae: a comparison between Salmonella enteritidis, E. coli and a nitrogen fixing strain of Klebsiella pneumoniae. J Appl Bacteriol 80, 458-464.

Ketley, J. M. (1997). Pathogenesis of enteric infection by Campylobacter. Microbiology 143, 5-21.

Kirchman, D. \& Mitchell, R. (1982). Contribution of particle-bound bacteria to total microheterotrophic activity in five ponds and two marshes. Water Res 21, 1237-1248.

Kuhn, E., van Loosdrecht, M. C. M., Giger, W. \& Schwarzenbach, R. P. (1987). Microbial degradation of nitrilotriacetate (NTA) during riverwater/groundwater infiltration: laboratory column studies. Water Res 21, 1237-1248.

LaPaglia, C. \& Hartzell, P. L. (1997). Stress-induced production of biofilm in the hyperthermophile Archaeoglobus fulgidus. Appl Environ Microbiol 63, 3158-3163.

Lazazzera, B. A. (2005). Lessons from DNA microarray analysis: the gene expression profile of biofilms. Curr Opin Microbiol 8, 222-227.

Nachamkin, I., Allos, B. M. \& Ho, T. (1998). Campylobacter species and Guillain-Barré syndrome. Clin Microbiol Rev 11, 555-567.

O'Farrell, P. H. (1975). High resolution two-dimensional electrophoresis of proteins. J Biol Chem 250, 4007-4021.

Palyada, K., Threadgill, D. \& Stintzi, A. (2004). Iron acquisition and regulation in Campylobacter jejuni. J Bacteriol 186, 4714-4729.

Park, S. F. (2002). The physiology of Campylobacter species and its relevance to their role as foodborne pathogens. Int J Food Microbiol 74, 177-188.

Pearson, A. D., Greenwood, M., Healing, T. D., Rollins, D., Shamat, M., Donaldson, J. \& Colwell, R. R. (1993). Colonization of broiler chickens by waterborne Campylobacter jejuni. Appl Environ Microbiol 59, 987-996.

Prigent-Combaret, C., Vidal, O., Dorel, C. \& Lejeune, P. (1999). Abiotic surface sensing and biofilm-dependent regulation of gene expression in Escherichia coli. J Bacteriol 181, 5993-6002.

Pysz, M. A., Conners, S. B., Montero, C. I., Shockley, K. R., Johnson, M. R., Ward, D. E. \& Kelly, R. M. (2004). Transcriptional analysis of biofilm formation processes in the anaerobic, hyperthermophilic bacterium Thermotoga maritima. Appl Environ Microbiol 70, 6098-6112.

Ratledge, C. \& Dover, L. G. (2000). Iron metabolism in pathogenic bacteria. Annu Rev Microbiol 54, 881-941.

Ren, D., Bedzyk, L. A., Setlow, P., Thomas, S. M., Ye, R. W. \& Wood, T. K. (2004a). Gene expression in Bacillus subtilis surface biofilms with and without sporulation and the importance of $y v e R$ for biofilm maintenance. Biotechnol Bioeng 86, 344-364.

Ren, D., Bedzyk, L. A., Thomas, S. M., Ye, R. W. \& Wood, T. K. (2004b). Gene expression in Escherichia coli biofilms. Appl Environ Microbiol 64, 515-524.

Russell, R. G. \& Blake, D. C., Jr (1994). Cell association and invasion of Caco-2 cells by Campylobacter jejuni. Infect Immun 62, 3773-3779.

Sampathkumar, B., Khachatourians, G. G. \& Korber, D. R. (2004). Treatment of Salmonella enterica serovar Enteritidis with a sublethal concentration of trisodium phosphate or alkaline $\mathrm{pH}$ induces thermotolerance. Appl Environ Microbiol 70, 4613-4620.

Schembri, M., Kjaergaard, K. \& Klemm, P. (2003). Global gene expression in Escherichia coli biofilms. Mol Microbiol 48, 253-267.

Stanley, K., Cunningham, R. \& Jones, K. (1998). Isolation of Campylobacter jejuni from ground water. J Appl Microbiol 85, 187-191.

Stanley, N. R., Britton, R. A., Grossman, A. D. \& Lazazzera, B. A. (2003). Identification of catabolite repression as a physiological regulator of biofilm formation by Bacillus subtilis by use of DNA microarrays. J Bacteriol 185, 1951-1957.

Stintzi, A., Marlow, D., Palyada, K., Naikare, H., Panciera, R., Whitworth, L. \& Clarke, C. (2005). Use of genome-wide expression profiling and mutagenesis to study the intestinal lifestyle of Campylobacter jejuni. Infect Immun 73, 1797-1810.

van Loosdrecht, M. C., Lyklema, J., Norde, W. \& Zehnder, A. J. (1990). Influence of interfaces on microbial activity. Microbiol Rev 54, 73-87.

van Vliet, A. H., Wooldridge, K. G. \& Ketley, J. M. (1998). Ironrepsonsive gene regulation in a Campylobacter jejuni fur mutant. J Bacteriol 180, 5291-5298.

Wang, Q., Frye, J. G., McClelland, M. \& Harshey, R. M. (2004). Gene expression patterns during swarming in Salmonella typhimurium: genes specific to surface growth and putative new motility and pathogenicity genes. Mol Microbiol 52, 169-187.

Whitely, M., Bangera, M. G., Bumgarner, R. E., Parsek, M. R., Teitzel, G. M., Lory, S. \& Greenberg, E. P. (2001). Gene expression in Pseudomonas aeruginosa biofilms. Nature 413, 860-864. 